\title{
Pós-verdade, cálculos e superfícies informadas: apontamentos para uma decodificação das imagens em
} rede

\author{
Jardel Orlandin \\ Mestre; Universidade do Vale do Rio dos Sinos, São Leopoldo, RS, Brasil \\ jardelorlandin@gmail.com \\ Sonia Montaño \\ Doutora; Universidade do Vale do Rio dos Sinos, São Leopoldo, RS, Brasil \\ soniam@unisinos.br
}

\begin{abstract}
Resumo
Formulamos, no ensaio, apontamentos para a decodificação de imagens técnicas. Apropriamo-nos de conceitos de Vilém Flusser como o design, a informação, a dúvida, o universo das imagens técnicas, a ontologia dos números, entre outros. Em uma livre apropriação teórico-metodológica, nós analisamos as chamadas imagens da pós-verdade, tentando perceber as linguagens que as realizam. No caso, utilizamos imagens sobre o atentado ao então candidato Jair Bolsonaro que circularam no Twitter. As imagens revelam uma incapacidade tecnocultural e política de dar a ver seus jogos e de admitir a dúvida, para multiplicar os mundos possíveis e habitáveis. Apontamos para a produção experimental de imagens como um modo de desafiar o aparelho contemporâneo e para a desinformação das imagens como um modo de decodificação e de aprendizado do cálculo, o que resulta em uma revolução cultural.
\end{abstract}

\section{Palavras-chave}

Decodificação. Informação. Imagens técnicas. Design. Vilém Flusser.

\section{Introdução}

Um termo vem ecoando cada vez mais nos últimos anos, ao ponto que o dicionário de Oxford o elegeu como o mais importante de 2016 (WORD..., 2016): pós-verdade. 0 substantivo é relacionado aos momentos nos quais fatos são menos importantes que as emoções e as crenças para a construção da opinião pública, sendo que o termo foi muito 
utilizado em debates políticos - tanto no plebiscito de permanência do Reino Unido na União Europeia quanto na campanha presidencial de 2016 dos Estados Unidos da América. Junto da expressão "pós-verdade", outros termos ganham força, como fake news - notícias falsas, em tradução livre - e misinformation - desinformação.

Com certeza a discussão sobre uma certa falsidade na informação, e sobre a rivalidade entre fatos e emoções ao pensar em questões como "verdade" ou "realidade" não é nova, dado que encontramos questionamentos aos exageros de jornais e outras publicações em textos dos séculos XIX e XX. Por um lado, Le Bon (2008) acredita que os estímulos mais simples e exagerados são mais suscetíveis ao contágio entre as massas e que, por isso, a fórmula "exagerar, afirmar e repetir" não precisa ser acompanhada de um raciocínio lógico. Para que uma ideia se torne dominante, continua Le Bon (2008), é necessário, inclusive, que ela se transforme e se torne simples, porquanto a sua aparência é mais decisiva, para sua adesão, do que a realidade. Sendo assim, caso seu sentido não esteja muito bem definido ou não seja definitivo - como é o caso de palavras como democracia, igualdade e liberdade -, a sua eficácia seria ainda maior, visto que cada receptor pode interpretar os discursos como bem entender.

Esses pontos encontram eco na obra de Tarde (2005), que discorre acerca do público que, suficientemente excitado, proclama vivas aos aliados e morte aos inimigos. Utilizando uma metáfora - não são os sinos afinados ou timbrados que são ouvidos à distância, todavia ou maiores - Tarde (2005) observa que as ideias mais aceitas pelas multidões são aquelas mais estreitas, as que impressionam os sentidos e que trazem emoções intensas, ainda que sejam falsas. Nem a verdade sobrevive, conclui Tarde (2005), quando "contraria a opinião" do público, que entende que tudo está submetido às suas ideias.

Se quiséssemos, poderíamos retroceder mais no tempo, uma vez que, conforme Victor (2017) notícias falsas seriam propagadas desde o século VI. Algumas das mais notórias atividades relacionadas ao tema teriam ocorrido nos séculos XVI e XVIII: contra cardeais que eram candidatos ao papado e em um período muito próximo à Revolução Francesa.

Agora, contudo, temos que considerar os diversos estágios da técnica nos séculos XIX, XX e, principalmente, no início do século XXI. Há diferenças entre os cenários descritos e a atual conjuntura. A tecnocultura ${ }^{1}$ contemporânea altera as experiências de compartilhar e publicar notícias. Igualmente, modifica a nossa capacidade de alterar, editar e manipular

\footnotetext{
${ }^{1}$ Usamos o termo tecnocultura conforme Fischer (2013). A partir de Flusser (2002) poderíamos pensar a tecnocultura como uma "caixa preta" a ser decifrada.
} 
informações, dados, fotos e vídeos, com dispositivos móveis que têm se tornado cada vez mais poderosos e com custos gradualmente mais baixos.

Além disso, ressaltamos o modo pelo qual as interfaces disponibilizam a informação. Fotos, textos, vídeos e quaisquer outros tipos de dados são, geralmente, acompanhados de botões que permitem - e interpelam - os usuários, para que eles intervenham naquela informação, mesmo que seja algo simples, como clicar nos ícones de "gostei" ou "não gostei", de salvar ou compartilhar. As interfaces estão programadas para legitimar e dar veracidade às imagens, na medida em que intervenções dos usuários geram novos compartilhamentos. É possível obedecer às interfaces ou fazer com que elas produzam outras informações. Essa é uma questão de liberdade.

Antes de prosseguimos, cabe ressaltar que a pós-verdade vem sendo estudada a partir de diversas perspectivas. Igualmente, existem diferentes pontos de partida para o estudo da comunicação política online.

Primeiro, destacamos que seria possível observar a participação de atores sociais que não fazem parte do cenário político tradicional, "oficial", conforme o fenômeno é descrito por Castells (2013). Nessa visão, se torna imprescindível investigar as plataformas web, os sites e o aparelho técnico no jogo político, principalmente, e na sociedade como um todo, os confrontos dessas tecnologias com a trama social.

Outra possibilidade seria o estudo dos movimentos sociais, a partir de Gohn (2014), e o impacto que as novas ferramentas possuem na organização, cooptação política e no agir desses grupos. Em diálogo e em sintonia com Castells (2013), poder-se-ia refletir sobre as mobilizações sociais e as transformações causadas, nas práticas, pelo advento da internet e dos sites de redes sociais, que facilitam o contato à distância e as manifestações de grupos de interesse ad hoc.

Há, atualmente, uma profusão de novos trabalhos que analisam qual a participação dos social bots ${ }^{2}$ na reverberação de acontecimentos em ambientes online, como o artigo de Shao et al (2017). Isso pois, embora perfis automatizados tendam a atuar junto de sites de desinformação e de notícias falsas, não é possível saber se uma parcela das visualizações e dos compartilhamentos de cada publicação não é realizada por perfis falsos ou social bots. 0 "impulso" numérico pode auxiliar tweets 3 , por exemplo, a se destacarem em um ambiente de

\footnotetext{
2 Social bots - ou robôs sociais, em tradução livre - são perfis automatizados em sites de redes sociais, nos quais máquinas assumem papéis destinados a seres humanos, como o ato de publicar um texto ou compartilhar notícias, por exemplo. ${ }^{3}$ Publicações no site de redes sociais Twitter.
} 
competição, além de auxiliar a legitimar - ou a dar sentidos de legítimo, de "verdadeiro" - o conteúdo das mensagens.

Como os conteúdos podem circular por ambientes opacos, como grupos de Facebook e WhatsApp, também é possível realizar pesquisas semelhantes ao trabalho de Wojcieszak (2011), que analisa a percepção de integrantes de grupos online politicamente homogêneos acerca da opinião pública. Ao acreditarem que as suas causas são publicamente relevantes, os usuários desses grupos se tornam mais ativos, manifestam-se mais, o que pode auxiliá-los a angariar um apoio que, até então, era fantasioso.

Outra perspectiva possível é investigar o evento por meio do prisma do espetáculo midiático. Como discorrem Mihalidis e Viotty (2017), as redes sociais online permitem que seus usuários encontrem ideias semelhantes às suas e que as repliquem e espalhem. Esses usuários são capazes de adicionar novas camadas de informação aos dados compartilhados, ampliando e fomentando o espetáculo. É um espaço, então, no qual é fácil e rápido defender valores, mormente quando as fontes "oficiais" estão desacreditadas e/ou são ignoradas.

Já Marchi (2012) discorre sobre uma nova geração de cidadãos, que não crê no jornalismo tradicional, porque o vê como um dispositivo incapaz de transmitir informações completas. Esse público prefere matérias personalizadas, menos objetivas, e que contenham opiniões sobre os fatos noticiados. Assim, a internet se transforma em um local importante para a busca de informações que auxiliem na compreensão dos acontecimentos: porque é possível - e fácil - encontrar atores sociais alinhados com esse ou aquele viés ideológico.

Enfim, quanto à informação audiovisual contemporânea, Chesney e Citron (2018), abordam os deepfakes - falsificação profunda, em tradução livre -, uma tecnologia capaz de manipular imagens, áudios e vídeos digitais com uma capacidade hiper-realista. É possível adulterar um vídeo e simular alguém dizendo e/ou fazendo algo que nunca ocorreu de fato. É viável substituir rostos, alterar faixas de áudio e elaborar conteúdos inteiramente novos. Mais importante que isso, todavia, é que o resultado final é convincente: parece real ou, ao menos, possível; principalmente quando olhamos para essas imagens como se elas não precisassem ser decodificadas.

Essa tecnologia não está presente somente em grandes estúdios de cinema, nas mãos de grandes empresas, pois tem se popularizado rapidamente. Existem softwares que atuam de maneira praticamente autônoma. Chesney e Citron (2018) narram o caso de um usuário do fórum online Reddit ${ }^{4}$ que conta como manipulou um vídeo pornográfico para colocar o 
rosto de uma ex-colega de trabalho em uma das personagens do filme. Para isso, foi preciso apenas coletar as fotos que a mulher havia postado e disponibilizado nos perfis que possuía nos sites de redes sociais do Facebook e do Instagram ${ }^{5}$ e as carregar em um programa. Ora, aplicativos disponíveis ao público são capazes de apreender, automaticamente, expressões faciais de alguém a partir de imagens estáticas para transformá-las em vídeos.

Percebemos, assim, que as fotos e os vídeos estão, gradualmente, perdendo seu "valor de verdade", também devido a características técnicas da imagem digital - no computador, textos, animações e vídeos documentais têm a mesma natureza, a programação numérica. E, para Flusser (2002), temos dificuldade para decifrarmos imagens porque não entendemos que elas são numéricas. Continuamos olhando para elas como se fossem textos - e os textos nós deciframos lendo, já os números nós deciframos calculando. Retomaremos essa ideia no final do artigo. Antes, adentraremos o modo em que o autor pensa as imagens.

Para Flusser (2002), existe uma diferença fundamental entre as imagens que nós produzimos hoje e aquelas que, há milênios, vínhamos produzindo - como as pinturas rupestres, os afrescos, os murais e os vitrais de igrejas. Uma qualidade que perdura é a abstração de dimensões e a intenção de apontar e representar alguma coisa que existe no mundo. Todavia é mister perceber que nós, seres humanos, já não produzimos as imagens diretamente, com as nossas mãos em contato com os materiais que compõem a obra. Hoje, trabalhamos com aparelhos técnicos que são programados para produzir essas imagens. As operações humano-aparelho resultam em imagens técnicas, que, por sua vez, parecem fiéis à realidade que intentam representar. Embora não o sejam, tais imagens são entendidas como "janelas" para o mundo: um único mundo, uma única realidade.

Para Flusser (2007), a cultura ocidental levou alguns séculos para intuir que a religião e a filosofia não são verdades fundamentais, mas sim modelos de compreensão do cosmos. Outros modelos, diferentes religiões e filosofias, podem coexistir sem que haja um critério, extra religioso ou extra filosófico, que garanta que um dos modelos seja o "mais verdadeiro". Concordamos com Ferreira (2018) que aponta que, para Flusser, língua e realidade se equiparam. Não há realidade fora da língua, as realidades aparecem exclusivamente nas línguas. Contudo, como lembra Ferreira (2018), o conceito de língua, para Flusser, é abrangente. Inclui tanto os idiomas, propriamente ditos, quanto imagens, sons, a ciência, o pensamento, a matemática, etc. "Nesse sentido, conhecimento, arte, verdade, religião e

${ }^{5}$ Para utilizar os sites, é preciso criar uma conta gratuita. Disponíveis, respectivamente, em: http://www.facebook.com e http://www.instagram.com/. Acesso em: 29 jul. 2019. 
filosofia são aspectos das línguas, logo, variam de acordo com a língua em que são - caso sejam - desenvolvidos", descreve Ferreira (2018, p. 40).

Nesse sentido, a língua seria a estrutura que transforma - dá forma (in-forma)- o caos em cosmos. Pensamos a pós-verdade como uma língua-realidade complexa, que imprime uma ordem ao caos e resulta em modelos. No caso que estudamos, um universo de diferentes línguas se encontra e se desencontra na pós-verdade: desde a língua portuguesa e o Brasil enquanto uma língua, a sua cultura, a política e a técnica, até o presente estágio das imagens técnicas, passando pelos modelos da tradição ocidental, tão carregados de janelas para o mundo, que insistem em nos convencer de que não precisamos decodificá-los.

São séculos de tradição, nos quais aprendemos a olhar o mundo através de janelas falsamente transparentes e que fazem com que o grito de Vilém Flusser continue ecoando com muito vigor. Imagens técnicas não são janelas para o mundo. Precisamos aprender a decodificar essas imagens. Logo, abordamos a pós-verdade enquanto um mundo codificado, programado por aparelhos pós-industriais, como imagens que precisam ser decodificadas.

E (de)codificar é uma questão de design.

\section{A madeira, a mesa e a informação: o design como decodificação}

Flusser (2013) pensava o processo de fabricação no sentido amplo, enquanto o ato de in-formar, de dar forma a algo. Uma vez fabricados, os objetos transformam o seu entorno pelo uso, e esse uso dá a ver um princípio que se torna um modelo. Nas carpintarias, algo amorfo como a madeira é informado em mesa. Nossos sentidos percebem a mesa. Uma mesa pode ser quadrada ou redonda; grande ou pequena; de madeira, de vidro ou de outros materiais; pode estar inteira, quebrada ou queimada. No entanto "atrás desses fenômenos encontram-se as formas eternas, imutáveis, que podemos perceber graças à perspectiva suprassensível da teoria", explica Flusser (2010, p. 23). Assim, a forma "mesa" seria real, e o conteúdo "mesa" que temos diante dos nossos olhos é aparente - isto é, aparece.

O design seria o responsável por nos mostrar que a matéria não aparece, a não ser que ela seja informada. Uma vez informada, a matéria se torna fenômeno. Se o design é o modo como a matéria é informada, e a informação faz a matéria aparecer, o design também nos permite fazer o caminho oposto: podemos perceber que formas informaram determinados fenômenos na sua aparência específica, na sua realidade. Reafirmamos, então, com Ferreira (2018, p. 44), que não é possível ver ou tocar as formas puras, a textura pura, porque "os seres humanos enxergam e tocam as coisas, quando elas passam a adquirir significado, pois 
ver e tocar já são modos de gerar significado - são nossos modos de apreender as coisas". Vamos, então, a essas formas, para tentar compreender os seus significados.

É de conhecimento público que, no dia 6 de setembro de 2018, durante um evento de campanha eleitoral na cidade de Juiz de Fora, no estado de Minas Gerais, o então candidato à Presidência da República Jair Bolsonaro foi esfaqueado na região abdominal e atendido em um hospital da cidade, onde passou por uma cirurgia. De acordo com o G1 (2018), após o atentado, Adélio Bispo de Oliveira foi identificado enquanto agressor e preso. Semanas mais tarde, discorrem Zuba e Freitas (2018), após a análise de mais de 250 gigabytes de arquivos, a Polícia Federal concluiu que Adélio, o autor do atentado, agiu sozinho.

Zuba e Freitas (2018) relatam, porém, que surgiram inúmeras publicações, em sites de redes sociais, que apontaram outras pessoas como apoiadoras ou coautoras do ataque. Tais denúncias continham dados imprecisos, expondo fatos e pessoas que não estão relacionados com o incidente. Certas publicações alcançaram tamanha repercussão que as pessoas que foram expostas se tornaram vítimas de ameaças e/ou ataques na internet e tiveram que registrar boletins de ocorrência, uma questão bastante habitual na forma que vem tomando as chamadas fake news.

Não temos experiência direta com esses fatos. Contudo eles podem ser encontrados em muitos veículos de comunicação, identificados com os mais diversos espectros políticos. 0 acontecimento é, desse modo, legitimado enquanto "verdadeiro" por diversas instituições, como os métodos de apuração jornalísticos, os próprios jornais e as já citadas investigações da Polícia Federal do Brasil, que dão uma forma a este fenômeno.

Tendo esses pressupostos em mente, seguimos ao Twitter ${ }^{6}$ - plataforma que se define enquanto "microblog" e permite a publicação de textos curtos, imagens, vídeos e links para outros sites - e recortamos algumas imagens relacionadas a este evento da interface da rede social. Para tanto, buscamos as publicações que continham qualquer um dos termos Jair, Bolsonaro, facada e atentado, entre os dias 6 e 9 de setembro de 2018 - ou seja, até o primeiro fim de semana após o fato. Nesse processo, pudemos observar várias narrativas, sendo que cinco delas fazem vasto uso de imagens:

1. Análises econômicas, midiáticas e/ou eleitorais;

2. Mensagens de apoio ao então candidato Jair Bolsonaro;

${ }^{6}$ Muitas funcionalidades do site são conferidas somente aos usuários que possuem uma conta, que pode ser criada gratuitamente. Disponível em: https://www.twitter.com/. Acesso em: 29 jul. 2019. 
3. Críticas às formas empregadas por diversos veículos de comunicação para a apresentação do ocorrido;

4. Teorias de que o fato não passaria de mera encenação, realizada pela própria equipe de Jair Bolsonaro com o intuito de angariar apoio, simpatia e votos ao então candidato; e

5. Teorias de que outras pessoas estariam envolvidas no ataque, que teria sido planejado por partidos políticos - com o intuito de assassinar o candidato ou forçar a sua retirada da corrida eleitoral.

Escolhemos a última das narrativas supracitadas por conta de sua repercussão online. Dentro das inúmeras imagens encontradas, optamos por aprofundar a análise em uma, a Figura 1.

Até aqui, operamos com procedimentos inerentes aos programas - o Twitter, a web e a língua portuguesa, por exemplo. Ligamos um dispositivo de conexão à internet, um computador desktop, acessamos a rede, entramos no site do Twitter, inserimos as palavraschaves que nos disponibilizaram uma quantidade de resultados, usamos um programa de captura de tela, etc. Sem aderirmos a esses processos programados, não teríamos acesso às imagens. Os atos de ver e de tocar, ou de codificar e de decodificar significados, passam pelo conhecimento dos aparelhos e dos programas. Apostamos no processo reverso, que parte da matéria aparente, da síntese, e refaz o caminho da informação que dá uma forma específica ao fenômeno e, com ela, cria modelos e reafirma formas imutáveis.

Figura 1 - Imagem do ataque ao candidato Bolsonaro publicada no perfil BolsoWoman AVENAoficial

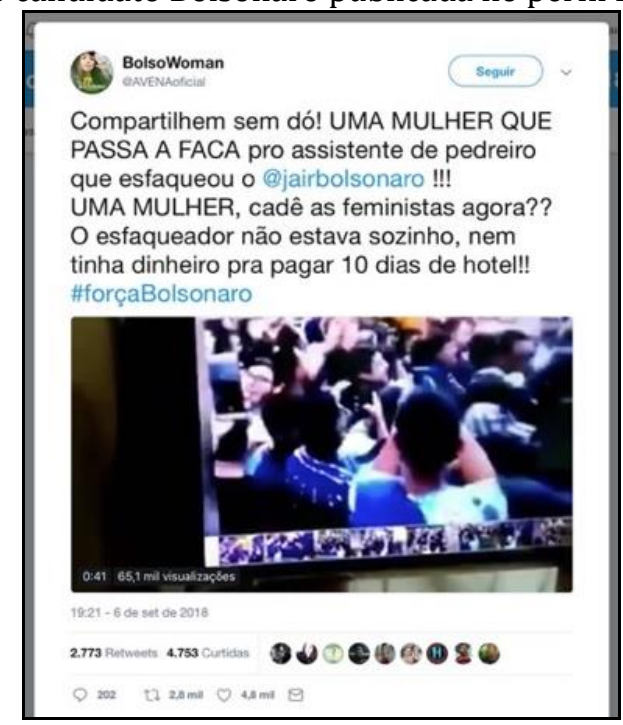

Fonte: TWITTER (2018) 
Ao longo deste texto, insistimos que decodificar o mundo passa pela concreticidade desse mundo, aquilo que nos aparece. A figura 1 nos apresenta uma interface recortada da plataforma Twitter, uma imagem produzida por aparelhos programados e inseridos em diversos meta-programas ${ }^{7}$.

Na figura 1, vemos uma pequena foto do lado superior esquerdo identificando o perfil AVENAoficial no Twitter com o nome de "BolsoWoman". Embora seja difícil de perceber, o tweet contém, além do texto, um vídeo que é uma gravação de um outro vídeo reproduzido em câmera lenta. Acontece uma narração sobre o áudio original, que ressignifica as imagens. Para podermos decodificar essas imagens, é importante levarmos em conta que o seu tempo é o tempo da superfície, um tempo mágico, conforme Flusser (2002). Isto é, podemos pensar tanto que o galo canta porque o sol nasce, quanto que o sol nasce justamente porque o galo o anuncia.

Esses movimentos circulares que nos permitiremos fazer para decodificar as imagens implodem o pensamento causalístico. 0 processo é amplamente produtivo para decodificar as imagens - ou seja, para construir um pensamento programático ${ }^{8}$.

\section{Forma primeira}

Temos a existência da rede mundial de computadores, que foi sendo informada ao longo de mais de 30 anos, e chegamos ao Twitter. Como já é praxe na internet, entramos através de um cadastro e ganhamos o que se chama de perfil. No site, há um limite de 280 caracteres para inserirmos textos, podemos publicar fotos e vídeos e vemos as postagens de muitos outros usuários, que seguimos. As postagens dos usuários, conhecidas como tweets, estão rodeadas de botões que permitem, entre outras operações, responder e retweetar a mensagem.

Não vem ao caso aprofundar de mais a própria rede. 0 que nos interessa é como ela é informada e informa, no caso em questão. Há marcas identitárias - resultado das relações entre língua e realidade - que no estágio da técnica na contemporaneidade reconhecemos rapidamente. Vemos o microblog, caso sejamos usuários do site, e as redes sociais como um

\footnotetext{
${ }^{7}$ Para Flusser (1983) cada vez que nos perguntamos pela origem de um programa nos esbarramos com um meta-programa. Devemos captar os programas em sua concreticidade cretina, a de um funcionamento programado absurdo, a fim de podermos compreendê-los e, dessa forma, inseri-los em meta-programas. 0 paradoxo é que tais meta-programas são jogos igualmente absurdos. Se quisermos emanciparmo-nos desse funcionamento, o que devemos aprender, então, é a admissão do absurdo: a liberdade é concebível somente enquanto jogo absurdo com os aparelhos. Mas isso é concebível apenas depois de termos assumido a política, e a existência humana em geral, como jogo absurdo. Sermos jogadores ou peças do jogo depende de aprendermos em tempo a sermos tais jogadores.

${ }^{8}$ Para Flusser (1967), a antropologia causalística vê no homem uma das espécies do ramo dos primatas, um elo da cadeia causal que estrutura o processo biológico. A antropologia programática vê no homem uma das permutações possíveis da informação genética comum a todos os entes vivos.
} 
todo. Uma possível falta de conexão interromperia definitivamente o funcionamento desse universo. 0 Twitter, as redes e o perfil visto são um grande elogia à conexão em rede. Viver é estar conectado.

\section{Forma segunda}

Temos o perfil AVENAoficial, com o nome "BolsoWoman". A inscrição "oficial” vem se tornando recorrente nas redes sociais, em perfis que pertencem a pessoas ou instituições conhecidas - supondo que existam outros perfis não oficiais ou falsos correspondendo aos mesmos. Por isso, o termo fake se torna muito presente na tecnocultura contemporânea, mesmo antes das fake news. 0 fake dá sentido ao oficial. 0 oficial e o fake se fortalecem.

Avena se declara enquanto jornalista e diretora de marketing carioca, com o perfil ativo desde 2009. 0 nome do perfil é escolhido pelos usuários. No caso, seria BolsoWoman. O nome remete ao candidato Bolsonaro e ao fato de ser mulher, contudo, o termo está em inglês. A adesão ao candidato parece estar junto de uma referência a uma super-heroína das histórias em quadrinhos, do cinema e da televisão: a Wonder Woman. A Mulher Maravilha da ficção, dotada de superpoderes, que luta contra o crime e a corrupção na cidade.

0 candidato Bolsonaro construiu a sua campanha com a ideia de combate à corrupção de um modo sui generis, sem contar com as instituições próprias da sociedade democrática ou dando a elas um outro papel. Da mesma maneira que a super-heroína ou os outros superheróis, que conseguem realizar, sozinhos, aquilo que instituições não são capazes de fazer. BolsoWoman estaria dividindo os créditos com o então candidato Jair Bolsonaro. A usuária, inclusive, abre mão dos seus superpoderes, colocando como primeiro nome o termo "Bolso", uma seguidora do super-herói ${ }^{9}$. 0 texto escrito pela usuária dá significado ao vídeo que ela posta. Neste caso, a superfície estabelece um limite claro de autoria entre o texto da usuária e o vídeo que ela posta, de autoria de outro alguém.

É característica do jogo da rede, permitindo compartilhar conteúdos que são dados novos. 0 texto apresenta alguns destaques, seja pelas palavras escritas em letras maiúsculas, seja pelos sinais de exclamação e interrogação, ou porque parte do texto se manifesta em azul, se distinguindo da escrita na cor preta. 0 texto remete mais à oralidade do que à língua escrita, o que é comum nos sites de redes sociais, e destaca uma informalidade que é própria de uma comunicação rápida, entre amigos e conhecidos.

${ }^{9}$ Para compreender melhor as formações do herói na cultura brasileira, ver Holanda (1995). 
A frase "compartilhe sem dó" abre essa mensagem. O chamado ao "compartilhamento" e o compartilhamento ${ }^{10}$, em si, são as principais lógicas operacionais das redes. As próprias mensagens são feitas para serem compartilhadas e ganham existência na dinâmica. Viver é permanecer conectado e compartilhar textos, vídeos e imagens, que são produzidos por nós ou pelos outros. A divulgação do compartilhamento tem uma forma individual, ágil e extra institucional, como comentado a partir de Castells (2013). Asssim, as redes se tornaram um caminho rápido de mobilização de grupos que previamente não estavam organizados e se unem por uma ou contra uma determinada causa.

E por que compartilhar sem dor? A afirmação "sem dó" projeta várias formas a essa matéria: uma expressão popular, uma retórica da simplicidade. Mas também demanda uma urgência e aponta para uma crença. Compartilhe sem pensar muito, sem perder tempo, em muitas de redes, com muitos de usuários. A rapidez de um compartilhar sem dó também impede a dúvida, aquela que, de acordo com Flusser (2011), poderia colocar em xeque uma certeza $^{11}$. E o que deve ser compartilhado sem compaixão?

A mensagem enfatiza a presença de uma mulher inserida na cena do atentado. 0 texto de BolsoWoman indica que é uma mulher quem passa a faca que protagonizou o atentado a Bolsonaro e questiona os movimentos feministas, dado que uma mulher estaria envolvida no crime. Independente de seguir em frente e ver o vídeo, o seu comparecimento, inclusive mudo, parece estar ali como testemunha, como certeza. E engendra certezas definitivas, que não estimulam a dúvida, mas a adesão e o compartilhamento. A certeza enquanto universo fechado, definitivo, que coincide com algo dado: uma mulher esteve na cena em questão, passando uma faca para o ataque contra aquele que combate a corrupção. Logo, a própria natureza da mulher, principalmente quando defendida - pelas feministas -, estaria presente naquela mulher, e seu discurso é levado à insignificância - perde seu significado. Há imagens que comprovam todas as premissas afirmadas.

Ainda, destacamos rapidamente duas expressões em azul. Uma inicia com o símbolo “@”, que é o modo pelo qual um perfil é mencionado na programação da interface. Esse perfil corresponde ao então candidato Jair Bolsonaro. A outra parte do símbolo "\#”, uma codificação que destaca uma ideia - no caso, de dar força ao candidato - e a associa com

\footnotetext{
${ }^{10}$ Compartilhar, um verbo com tantos significados, adquire, nas redes, a forma de acessar um link e, assim, disponibilizar para visualização de outros usuários a mensagem compartilhada.

11 Ao contrário de outros autores, Flusser (2011, p 21) não vê a dúvida intelectual como um lugar provisório para buscar certezas absolutas e sim como um exercício saudável: "A dúvida é um estado de espírito polivalente. Pode significar o fim de uma fé, ou pode significar o começo de outra. Pode ainda, se levada ao extremo, ser vista como 'ceticismo', isto é, como uma espécie de fé invertida. Em dose moderada estimula o pensamento. Em dose excessiva paralisa toda a atividade mental. A dúvida, como exercício intelectual, proporciona um dos poucos prazeres puros, mas como experiência moral ela é uma tortura".
} 
todos os outros tweets que também a contém. De alguma maneira, esses fenômenos se tornam modelos, e os símbolos “\#” se referem a formas de pertença a mundos construídos nestas redes, tão fluídos e líquidos quanto a própria rede.

Sem pretensão de cansar nosso leitor na decodificação da informação, é preciso passar por mais duas superfícies aqui projetadas.

\section{Forma terceira}

Um vídeo que contém um outro vídeo. Observamos o enquadramento de duas mãos segurando um celular, no qual roda o vídeo. Ouvimos uma voz - talvez a voz e as mãos sejam da mesma pessoa, mas nada dá a ver esse usuário como tal. Uma voz off ${ }^{12}$, masculina, narra fatos que o narrador vê. Às vezes, as mãos mexem no dispositivo no qual rodam as imagens para mostrar - ao mundo? - aquilo que não podemos ver quando vemos só um grupo de pessoas em movimento. Enquanto as imagens se sucedem, o narrador externo afirma, por cima da narração do vídeo original:

a mulher passa, finge que não conhece o cara... o... passou a faca para ele... olha lá, a faca na mão dele, não dá para ver porque a faca é preta... esse cara de camiseta branca passa a faca para o tal do Adélio... e agora ele vai lá e dá a facada... depois ele passa a faca para outro cara, por isso a polícia não encontrou a faca.

O vídeo está inconcluso - essa voz desaparece subitamente - e está editado, deixando uma parte das imagens fora de foco. Há o foco no celular em que rodam as imagens de forma desenquadrada e tremida - bem próprio do modo como o celular dá forma às imagens, tanto pelas suas características de leveza quanto pelo movimento do corpo que leva Cunha (2010) a chamá-las de imagens sem gravidade.

Há, ainda, na forma dessas imagens, uma questão importante que, de certo modo, fica escondida. Alguém está produzindo o vídeo do usuário que segura o celular e o comenta, já que as suas duas mãos estão no celular. 0 vídeo, com os seus comentários, não poderia ser gravado sozinho, embora no conjunto dessas imagens está inscrito como um gesto natural, que reforça a sua inquestionabilidade.

Como um narrador de futebol que narra um jogo, a voz off leva a uma única relação causalística e incontestável. Como uma prestação de serviço de olhar, do dispositivo e o do usuário, que estendem o olho de um terceiro - aquele com quem compartilham - para ver o

12 Sobre a relação imperceptivelmente autoritária instaurada entre a voz off e as imagens, ver Canevacci (2001). 
que não é visível por si, porém - e até por causa disso - é verdade. 0 destaque agora não está na mulher, nas mulheres e nos movimentos feministas, mas sim na participação de outros protagonistas no atentado.

A (pós-)verdade precisa ser narrada, não se percebe pelos próprios sentidos, mas se confirma pelas suas testemunhas. Ao contrário da ciência positivista, porta-voz da verdade durante mais de um século, os porta-vozes da pós-verdade estão longe da ciência e de outras instituições como a justiça ou o jornalismo. Contudo, e ao mesmo tempo, essa verdade, como construída nos séculos XIX e XX, comparece pelo avesso na superfície em questão.

\section{Forma quarta}

Por último, temos o vídeo que está sendo exibido dentro do celular, que é segurado e comentado por alguém, e compartilhado e comentado no perfil de BolsoWoman no Twitter. No vídeo, podem ser vistas imagens de pessoas que se movimentam rapidamente de forma desenquadrada - ora as imagens "cortam" cabeças, ora se dirigem ao chão - e tremida, como é próprio das imagens de celular. Também podemos escutar uma voz, que narra essa cena, provavelmente a voz da pessoa que estava filmando e que estava próxima do acontecimento. Podemos perceber que o som e as imagens do vídeo, que roda dentro do celular, comentam sobre a passagem da faca de uma mão para outra antes e depois do atentado.

A ênfase, aqui, está na razão pela qual a polícia não encontrou a faca, que passou para outra mão depois do atentado. Em contraste com a confusão das imagens, produzida na pósedição, a técnica de câmera lenta parece estar colaborando para que possamos ver "melhor" aquilo que o relator diz estar vendo. Embora o efeito de tornar o movimento mais lento não permite ver o que não está nas imagens - poderia estar fora de quadro ou simplesmente não existir -, a presença da câmera lenta está apontando para uma "lentização" do tempo como um sinônimo de ver, seguindo a tradição dos efeitos nas imagens técnicas. A verdade é a verdade dos aparelhos, dos jogos pós-industriais, do universo de imagens técnicas, no qual compartilhar uma coisa é um modo de protagonizar algo que está dado e que, de modo algum, revela o seu jogo.

Vale destacar que é bem possível que existam outras versões do material circulando por sites na internet. Além disso, a resolução final dos vídeos é baixa, por conta das múltiplas camadas de gravação. Essas características não impediram a disseminação dos conteúdos. A publicação que aparece na Figura 1, voltando à superfície como um todo, teve quase 200 comentários, três mil compartilhamentos, 4,5 mil "curtidas" e 65 mil visualizações. Tais números são respostas aos modos de programação da interface do programa e relativos a 
esse material. Reforçamos, porém, que é possível que o vídeo circule por outros perfis no Twitter e por outros sites e plataformas web, como o Facebook, o YouTube e o WhatsApp ${ }^{13}$.

Lembramos, com Flusser (2010, p. 31), que se antes o objetivo era formalizar o mundo existente, agora "o objetivo é realizar as formas projetadas para criar mundos alternativos. Isso é o que se entende por 'cultura imaterial', mas deveria na verdade se chamar 'cultura materializadora'”.

\section{Os aparelhos e a questão da liberdade}

O jogo seria, para Flusser (1967), uma resposta humana à seriedade cretina da vida e da morte. Enquanto jogador, o homem se rebela contra essa seriedade. E esse homem se tornaria mais rebelde conforme participaria de mais e mais jogos. A pós-indústria exige adentrar no funcionamento dos aparelhos, que são brinquedos que simulam um tipo de pensamento. Flusser (2002) parte do aparelho fotográfico, no entanto entende que as suas afirmações em relação a esse aparelho podem ser estendidas a todo e qualquer aparelho.

O autor chama atenção especialmente para a prática dos fotógrafos experimentais, porque eles sabem que a sua práxis é dirigida contra os aparelhos. Eles tentam obrigar o aparelho a produzir imagens informativas que não estão em seu programa. Para Flusser (2002), na filosofia da fotografia - e dos aparelhos em geral -, o que está sendo discutido é o problema da liberdade. Segundo Flusser (2002, p. 76), há a urgência de uma filosofia da fotografia para que a práxis fotográfica seja conscientizada nos seguintes termos:

A conscientização de tal práxis é necessária porque, sem ela, jamais captaremos as aberturas para a liberdade na vida dos funcionários dos aparelhos. Em outros termos: a filosofia da fotografia é necessária porque é reflexão sobre as possibilidades de se viver livremente num mundo programado de aparelhos.

Os que jogam com aparelhos - fotográfico, televisivo, da internet, etc. - agem em prol do esgotamento dos programas e em prol da realização do universo - fotográfico, televisivo, da internet, etc. -, esforçando-se por descobrir potencialidades ignoradas. Brincam, porque procuram por novos lances, como um enxadrista. Não estão preocupados em modificar o mundo, contudo em obrigar o aparelho a revelar as suas potencialidades.

${ }^{13}$ Disponíveis, respectivamente, em: http://www.facebook.com/, http://www.youtube.com/ e http://www.whatsapp.com/. Acesso em: 29 jul. 2019. 
O fato de termos tantos dispositivos de produzir quaisquer formas de imagens e sons - e, inclusive, de fazer alguém dizer alguma coisa - indica que nós estamos longe de dirigir os nossos esforços para decodificar as imagens e dar lugar à dinâmica da dúvida. 0 campo da comunicação e, particularmente, da comunicação audiovisual pode ter uma contribuição decisiva na alfabetização das imagens técnicas e na descoberta de potencialidades ignoradas que o atual cenário tecnocultural oferece.

Nesse sentido, podemos voltar às imagens que ocupam esse ensaio, imagens técnicas da pós-verdade, e pensá-las a partir da liberdade. De quantos jogos elas participam? Elas auxiliam a descobrir potencialidades ignoradas ou recorrem aos universos conhecidos? Qual a capacidade que as imagens revelam de constantemente abrir ou desvendar os seus jogos?

Enquanto imagens técnicas, elas dialogam com todo o universo das imagens que pretendem representar o mundo. Enquanto interfaces gráficas programadas para acesso a internet por um dispositivo, dialogam com todo o mundo desses códigos de conexão, compartilhamento e de edição de conteúdo. Enquanto imagens técnicas do atentado ao candidato Bolsonaro, dialogam com um universo de imagens específicas que circularam e ainda circulam em diversos processos midiáticos independente do que afirmam. Enquanto imagens da pós-verdade, elas parecem dialogar com imagens do campo religioso, da publicidade, do esporte profissional e inclusive do jornalismo, quando estas imagens apelam à inserção de uma certeza, negando o direito à dúvida (FLUSSER, 2007). Enquanto jogos de aparelhos programados, essas imagens dialogam com aquelas que não exploram potencialidades do aparelho e se esforçam por esconder seus jogos.

As imagens da pós-verdade potencialmente incluem na sua superfície tantos conceitos de verdade, de realidade e de janelas para o mundo presentes na cultura ocidental. Quanto mais nos familiarizarmos com imagens experimentais, que abrem múltiplos mundos, que revelam os seus jogos e meta-jogos, mais treinados estaremos para compreender o estágio atual da técnica e o grande legado de Vilém Flusser. Aprenderemos a lidar com os números, que constituem as ontologias das imagens e da contemporaneidade. A transcodificação de números em cores, formas e tons por meio de computadores teria tornado a beleza e a profundidade do cálculo perceptíveis aos sentidos.

Seria pouco proveitoso desprezar esses mundos projetados sinteticamente como ficções ou simulações do mundo efetivo [eigentlichen]. (...) Portanto, ou os mundos projetados são tão reais [wirklich] quanto o "efetivo" (caso possam reunir os pontos com a mesma densidade com que o faz este último), ou o mundo percebido como "efetivo" é tão fictício quanto os mundos projetados. A revolução cultural hoje consiste no fato de que nos 
tornamos aptos a construir mundos alternativos e paralelos a este que nos foi supostamente dado; de que, de sujeitos de um único mundo, estamos nos convertendo em projetos de vários mundos; e de que começamos a aprender a calcular (FLUSSER, 2013, p. 85).

Se o mundo consiste em uma dispersão de partículas, seria porque o engendramos de modo a adaptá-lo aos nossos cálculos, sendo que, desde os filósofos gregos, o mundo era descrito alfabeticamente. Esse mundo era engendrado para se adaptar às regras do discurso lógico e não às regras da matemática. Se decodificarmos essas imagens sem cessar, talvez aprendamos a calcular e a potencializar a multiplicidade de mundos, realidades e verdades nas quais já estamos projetados.

E esse é um desafio político.

\section{Referências}

AVENA. [Compartilhem sem dó!]. Brasil, 6 set. 2018. Twitter: @AVENAoficial. Disponível em: https://twitter.com/AVENAoficial/status/1037888570617475072. Acesso em: 29 jul. 2019.

CANEVACCI, Massimo. Antropologia da comunicação visual. Rio de Janeiro: DP\&A, 2001.

CASTELLS, Manuel. Redes de indignação e esperança: movimentos sociais na era da internet. Rio de Janeiro, RJ. Zahar, 2013.

CHESNEY, Robert; CITRON, Danielle Keats. Deep fakes: a looming challenge for privacy, democracy, and national security. 14 jul. 2018. U of Texas Law, Public Law Research Paper No. 692; U of Maryland Legal Studies Research Paper No. 2018-21. Disponível em: https://ssrn.com/abstract=3213954.

CUNHA, Oswaldo Norbin Prado. O celular e as novas estéticas audiovisuais. 2010.

Dissertação (Mestrado em Ciências da Comunicação) -- Programa de Pós-Graduação em Ciências da Comunicação. Universidade Federal de Minas Gerais, Belo Horizonte, MG, 2010.

DUBOIS, Philippe. Cinema, vídeo, Godard. São Paulo: Cosac Naify, 2004.

FERREIRA, Débora Pazetto. Vilém Flusser, um filósofo da linguagem brasileiro.

Trans/Form/Ação. Marília, vol.41 no.2 abr./jun. 2018.

FISCHER, Gustavo Daudt. Tecnocultura: aproximações conceituais e pistas para pensar as audiovisualidades. In: Kilpp, Suzana; Fischer, Gustavo Daudt. (Org.). Para entender as imagens: como ver o que nos olha? 1ํㅡ edição. Porto Alegre: Entremeios, 2013. 216p.

FLUSSER, Vilém. Jogo. Suplemento Literário OESP. 9/16/1967. Disponível em: http://www.cisc.org.br/portal/biblioteca/jogos.pdf. Acesso em 10/01/2006. 
FLUSSER, Vilém. Pós-História: vinte instantâneos e um modo de usar. São Paulo: Duas Cidades, 1983.

FLUSSER, Vilém. Filosofia da caixa preta. São Paulo: Editora Hucitec, 2002.

FLUSSER, Vilém. Língua e realidade. São Paulo: Annablume, 2007.

FLUSSER, Vilém. 0 mundo codificado: por uma filosofia do design e da comunicação. Organizado por Rafael Cardoso. Tradução Raquel Abi-Sâmara. São Paulo: Cosac Naify, 2013.

GOHN, Maria da Glória. Sociologia dos movimentos sociais. 1a edição. São Paulo: Cortez, 2014. (Questões da nossa época; v. 47)

HOLANDA, Sérgio Buarque de. (1902-1982), Raízes do Brasil. 26ª Edição - São Paulo - SP: Companhia das Letras, 1995.

JAIR Bolsonaro leva facada durante ato de campanha em Juiz de Fora. G1, Juiz de Fora, 6 set. 2018. Disponível em: https://g1.globo.com/mg/zona-da-mata/noticia/2018/09/06/ato-decampanha-de-bolsonaro-em-juiz-de-fora-e-interrompido-apos-tumulto.ghtml. Acesso em: 29 jul. 2019.

LE BON, Gustave. Psicologia das multidões. Tradução Mariana Sérvulo; revisão da tradução Claudia Berliner. São Paulo: Editora WMF Martins Fontes, 2008. (Coleção Tópicos)

MARCHI, Regina. With Facebook, blogs, and fake news, teens reject journalistic "objectivity". Journal of Communication Inquiry, v. 36, n. 3, p. 246 -262, 2012.

MIHAILIDIS, Paul; VIOTTY, Samantha. Spreadable Spectacle in Digital Culture: Civic Expression, Fake News, and the Role of Media Literacies in "Post-Fact" Society. American Behavioral Scientist, v. 61, n. 4, p. 441-454, 2017.

SHAO, Chengcheng; CIAMPAGLIA, Giovanni Luca; VAROL, Onur; FLAMMINI, Alessandro; MENCZER, Filippio. The spread of fake news by social bots. Indiana University, Bloomington. 16 p. 2017.

TARDE, Gabriel de. A opinião e as massas. Tradução Eduardo Brandão. 2ª ed. São Paulo: Martins Fontes, 2005. (Coleção tópicos)

VICTOR, Fabio. Notícias falsas existem desde o século 6, afirma historiador Robert Darnton. 19 fev. 2017. [S. l.]. Folha de São Paulo. Disponível em: http://www1.folha.uol.com.br/ilustrissima/2017/02/1859726-noticias-falsas-existemdesde-o-seculo-6-afirma-historiador-robert-darnton.shtml. Acesso em: 29 jul. 2018.

WOJCIESZAK, Magdalena Elzbieta. Computer-mediated false consensus: radical online groups, social networks and news media. Mass Communication and Society, 14:4, p. 527 546, 2011. DOI: 10.1080/15205436.2010.513795.

WORD of the year 2016 is... Oxford Dictionaries, [S. 1.], 2016. Disponível em: https://en.oxforddictionaries.com/word-of-the-year/word-of-the-year-2016. Acesso em: 29 jul. 2019. 
ZUBA, Fernando; FREITAS, Raquel. Agressor de Bolsonaro agiu sozinho no momento do crime e por motivação política, conclui PF. 28 set. 2018. Belo Horizonte. TV Globo e G1 MG. Disponível em: https://g1.globo.com/mg/minas-gerais/noticia/2018/09/28/suspeito-deesfaquear-bolsonaro-agiu-sozinho-no-momento-do-crime-e-por-motivacao-politica-concluipf.ghtml. Acesso em: 29 jul. 2019.

\title{
Post-truth, calculations and informed surfaces: notes for decoding images on network
}

\begin{abstract}
In the essay, we formulated notes to decode technical images. We adapt and use Vilém Flusser's concepts, such as design, information, doubt, the universe of technical images, the ontology of numbers, among others. In a free theoreticalmethodological appropriation, we analyze the so-called posttruth images, trying to understand the languages that make them happen. In this case, we used images about the attack to Jair Bolsonaro, then a candidate, that circulated on Twitter. The images reveal a technocultural and political inability to show their games and to admit doubt, in order to multiply the possible and habitable worlds. We point to the experimental production of images as a way to challenge the contemporary apparatus and to the disinformation of images as a way of decoding and learning calculus, which results in a cultural revolution.
\end{abstract}

\section{Keywords}

Decoding. Information. Technical images. Design. Vilém Flusser.

Recebido em 30/05/2020

Aceito em 20/08/2020 